Fueyo et al.

\title{
Jumonji family histone demethylases in neural development
}

Raquel Fueyo*, María Alejandra García*, Marian A. Martínez-Balbás\#

Department of Molecular Genomics. Instituto de Biología Molecular de Barcelona (IBMB), Consejo Superior de Investigaciones Científicas (CSIC). Parc Científic de Barcelona (PCB). Barcelona 08028, Spain.

* Equally contributing authors

\#Corresponding author

E-mail: mmbbmc@ibmb.csic.es

Tel.: (+34) 93403 4961. Fax: (+34) 934034979 
Fueyo et al.

\begin{abstract}
Central nervous system (CNS) development is driven by coordinated actions of developmental signals and chromatin regulators that precisely regulate gene expression patterns. Histone methylation is a regulatory mechanism that controls transcriptional programs. In the last 10 years, several histone demethylases (HDM) were identified as important players in neural development, and their implication in cell fate decisions is beginning to be recognized. Identification of the physiological roles of these enzymes and their molecular mechanisms of action will be necessary for completely understanding the process that ultimately generates different neural cells in the CNS. In this review, we provide an overview of the Jumonji family of HDMs involved in neurodevelopment, and we discuss their roles during neural fate establishment and neuronal differentiation.
\end{abstract}

\title{
Keywords
}

Histone demethylation, Jumonji family, neural specification, neuronal differentiation, developmental signals

\section{Introduction}

The CNS is formed by different cell types that are generated during neural development. Neural progenitor cells (NPCs) proliferate to maintain their population, and at the same time, they differentiate, first to generate neurons, then oligodendrocytes and astrocytes (Guillemot, 2005). These complex processes occur in response to a variety of developmental cues, and their completion requires close coordination between transcription factors, extrinsic signals, and chromatin-modifying enzymes. The developmental signals and transcription factor families that control neurogenesis have been studied for many years, and they are quite well established (Lee and Pfaff, 2001, 
Guillemot, 2007). However, recently, factors that interact with chromatin have emerged as regulators of neurogenesis and neural development. During the last decade, great efforts have been made to elucidate the role of epigenetic regulators that govern the transcriptional programs involved in neural development.

Eukaryotic DNA is organized into nucleosomes; this organization provides both a compact package of genetic material and a new layer of regulation for controlling its activity. Each nucleosome is composed of a DNA strand of 145-147 base pairs and two molecules each of histones H3, H4, H2A, and H2B. Moreover, the linker histone, H1, is required to compact the chromatin into high-order structures (Luger, 2003, Kouzarides, 2007). The amino-terminal domains of $\mathrm{H} 3, \mathrm{H} 4, \mathrm{H} 2 \mathrm{~A}$, and $\mathrm{H} 2 \mathrm{~B}$ undergo different types of post-translational modifications, mainly acetylation, methylation, phosphorylation, ubiquitination, and sumoylation (Kouzarides, 2007, Bannister and Kouzarides, 2011). These modifications evoke dynamic changes in the chromatin structure, which are essential for responding to both extrinsic and intrinsic signaling cues. In many cases, these responses lead to changes in gene expression that ultimately control transcriptional programs during development.

Although histone acetylation is the most studied and characterized histone modification (Kouzarides, 2007, Bannister and Kouzarides, 2011), in the last few years, many enzymes that catalyze the addition or removal of methyl groups from histones have been identified and widely studied. Methylation of histones can occur on lysine $(\mathrm{K})$ and arginine $(\mathrm{R})$ residues; in addition, $\mathrm{K}$ residues can undergo mono- (me1), di(me2), or tri-methylation (me3), and $\mathrm{R}$ residues can undergo me1 and me2, positioned either symmetrically or asymmetrically. 
For many years, it was believed that histone methylation was an irreversible modification, and that the removal of methyl groups required a histone exchange. However, the finding that histone methylation patterns could respond to many signals in a reversible manner suggested that methylation/demethylation is a much more dynamic process than previously thought. The identification of the first histone demethylase (HDM) in 2004 (Shi, et al. 2004) confirmed this possibility. During the last decade, many HDMs have been identified (Table1). They were classified into two families: (i) the KDM1 family, whose members demethylate $\mathrm{H} 3 \mathrm{~K} 4 \mathrm{me} 2 / 1$ and $\mathrm{H} 3 \mathrm{~K} 9 \mathrm{me} 2 / 1$ in a flavin-adenine-dinucleotide dependent reaction (Shi, et al. 2004, Metzger, et al. 2005, Ciccone, et al. 2009); and (ii) the Jumonji (JMJC) family (Jumonji-c domain containing proteins), whose members utilize $\mathrm{Fe}(\mathrm{II})$ and 2-oxoglutarate in the demethylation reaction. The first JMJC HDM was identified in 2006 (Tsukada, et al. 2006). Since then, this family has greatly grown in number, and it includes enzymes that target me1, me2, and me3 histones [(Kooistra and Helin, 2012), Table 1].

Histone methylation is associated with both transcriptional activation (H3K4me3, H3K36me3, and H3K79me3/me2/me1) and repression (H3K9me3/me2, H4K20me3, and H3K27me3/me2). Interestingly, a combination of active and repressive histone methylations occurs in many promoters, and mainly in embryonic stem cells (ESCs). In particular, sites that carry H3K27me3 are often also enriched in H3K4me3. Sites marked by this combination of histone modifications with opposite regulatory potential are called bivalent domains, and they are thought to be responsible for maintaining genes in a poised state for activation (Azuara, et al. 2006, Bernstein, et al. 2006). Accordingly, many chromatin-acting complexes contain both histone methyltransferases (HMT) and HDMs that catalyze functionally opposing modifications. For example, the one comprising MLL3-MLL4 H3K4me3 HMTs 
combined with a H3K27me3 HDM, UTX (Agger, et al. 2007, Lee, et al. 2007b); another containing a H3K4me3 HDM, JARID1A (jumonji, AT-rich Interactive domain 1A) together with polycomb responsive complex 2 (PRC2), which is responsible for H3K27me3 methylation (Pasini, et al. 2008). These close associations might facilitate coordinated chromatin modifications and ensure methylation balance is maintained for regulating proper development. Moreover, histone methylation occurs together with other histone modifications, mainly histone acetylation. Accordingly, HDMs are present in large protein complexes that often contain other histone-modifying enzymes; for example, the JARID1C $\mathrm{H} 3 \mathrm{~K} 4 \mathrm{me} 3 / \mathrm{me} 2 \mathrm{HDM}$ is associated with histone deacetylases (HDAC) HDAC1 and HDAC2, the HMT G9a, and the transcriptional repressor REST [(Tahiliani, et al. 2007), see below]. These associations facilitate coordinated interactions of different enzymes with multiple histone sites. Then, although a particular modification might correlate with either transcription activation or repression, the combination of histone modifications will determine the final biological output (de la Cruz, et al. 2005, Taverna, et al. 2007, Lois, et al. 2010).

During the last few years, it was proposed that HDMs played a central role in development, particularly in a neural context, and in diseases (Lee and Lee, 2010, Pedersen and Helin, 2010, Pattaroni and Jacob, 2013) (Table 2). However, we are just beginning to understand the molecular mechanisms through which HDMs cooperate with signals, to coordinate neural development. In this review, we briefly summarize the roles of Jumonji family members in different aspects of neurogenesis. In addition, we will highlight the major questions that remain open for future investigation.

\section{Function of Jumonji demethylases in neural development}


The first identified protein containing Jumonji-c domain was JARID2 that interestingly lacks the histone demethylase activity. However, it is essential for normal embryonic development and in particular for neural development (Landeira and Fisher, 2011). JARID2 associates with PRC2 to facilitate the latter's recruitment to target genes (Peng, et al., 2009, Shen, et al., 2009, Pasini, et al., 2010). As PRC complexes are required at different steps of neurogenesis, JARID2 might contribute to neural development by regulating PRC recruitment. The rest of proteins with a Jumonji-c domain are catalytically active and they are classified into subfamilies (HDM2/7). Each one contains different enzymes that target a particular lysine/s mainly on histones H3 and H4. They are highly specific for both $\mathrm{K}$ residues and degree of methylation (Table 1). Recently, many reports highlight the importance of the equilibrium between HMT and HDM enzymatic activities in the control of the final state of histone methylation during neural development. This is a key determinant of both neural commitment in ESCs and cell fate determination in NSCs. In accordance with that notion, many reports have proposed an essential role of PRC2 during neural development. PRC2 occupies and represses many neural-developmental regulators in ESCs (Boyer, et al. 2006, Bracken, et al. 2006, Lee, et al. 2006); moreover, H3K27me3 levels decrease in many neural-specific genes during neural differentiation (Boyer, et al. 2006, Burgold, et al. 2008). PRC complexes are also required for NPCs differentiation. High levels of Enhancer of Zeste Homologue 2 (EZH2), the enzyme in PRC2 that methylates H3K27me3/me2, are required for NPC differentiation to oligodendrocytes. Conversely, Ezh2 expression decreases to allow neuronal and astrocytic differentiation (Sher, et al., 2008). Finally, during the neurogenic to astrogenic transition, PRC proteins suppress neurogenic competence of NPCs by inhibiting Neurog 1 expression. At the late stage of 
NPCs, histone acetylation of the Neurog 1 promoter decreases and H3K27me3 increases leading to repression of Neurog1 (Hirabayashi, et al., 2009).

Another good example remarking the importance of the balance between the histone methylation and demethylation is the regulation of the GFAP promoter during differentiation of NPCs into astrocytes. At this stage of development, FGF2 induces the decrease of $\mathrm{H} 3 \mathrm{~K} 9 \mathrm{me} 3$ and the increase of $\mathrm{H} 3 \mathrm{~K} 4 \mathrm{me} 3$ levels on the GFAP promoter leading to the activation of this astrocyte-specific marker (Song and Ghosh, 2004).

In this review we will discuss the function of the different HDMs controlling the histone methylation levels during neural development. Among them, we will mainly focus on those targeting $\mathrm{H} 3 \mathrm{~K} 4$ and $\mathrm{H} 3 \mathrm{~K} 27$ sites, because they have been associated with the major neural phenotypes.

\section{KDM5 Subfamily}

The KDM5 subfamily members catalyze the demethylation of $\mathrm{H} 3 \mathrm{~K} 4 \mathrm{me} 3 / \mathrm{me} 2$ (Christensen, et al. 2007, Iwase, et al. 2007, Klose, et al. 2007, Lee, et al. 2007a, Tahiliani, et al. 2007, Yamane, et al. 2007). The mammalian family comprises the JARID1A-D proteins (Table 1). These enzymes, particularly JARID1B and C, are involved in different aspects of neural development.

Recent work with JaridlB knockout mouse embryos revealed that this HDM performs essential functions in neural development. Deletion of Jarid1B led to several neural defects, including disorganized cranial nerves, defects in eye development, and an increased incidence of exencephaly (Albert, et al. 2013). JARID1B binds to neural master regulator genes such as Pax6 and $\operatorname{Otx} 2$, to maintain low levels of H3K4me3. In 
Jarid1B KO embryos, increased levels of H3K4me3 were associated with both repressed and bivalent genes, which made these genes more susceptible to activation (Albert, et al. 2013) (Fig. 1). Furthermore, ESCs require JARID1B activity for proper differentiation into neurons (Schmitz, et al. 2011). On the other hand, Jarid1B overexpression in ESCs decreased the expression of other genes that regulate cell fate decisions, like Egrl, p27, and BMI1. These findings demonstrated that JARID1B plays an important role in balancing proliferation and differentiation during development (Dey, et al. 2008).

The best-known member of the KDM5 subfamily is JARID1C. JARID1C is strongly related to X-linked mental retardation (XLMR) and epilepsy (Jensen, et al. 2005, Tzschach, et al. 2006, Tahiliani, et al. 2007, Jensen, et al. 2010). The mutations found in patients with XLMR frequently compromise JARID1C HDM activity (Iwase, et al. 2007, Tahiliani, et al. 2007). Shi's group has shown that, in combination with REST, G9a, and HDAC1/2, JARID1C repressed a subset of the REST target genes by binding to the neuron-restrictive silencing elements in their promoters. Thus, the JARID1C/REST complex maintains the neuronal genes silenced in non-neuronal cells. Additionally, when JaridlC was knocked down in primary rat cerebellar granule neurons, dendritic morphogenesis was impaired. Moreover, studies in zebrafish demonstrated that Jarid1C plays a role in brain-patterning establishment and neuronal survival (Iwase, et al. 2007).

Taken together, the published data indicate that the JARID1 family is critical for normal neural development. Its major role is to fine-tune the expression of important neural regulators by maintaining appropriate $\mathrm{H} 3 \mathrm{~K} 4 \mathrm{me} 3$ levels to ensure a balance between active and repressive histone modifications. An alteration in this balance can 
affect phenotypical outcome when the developmental transcription potential takes advantage of that.

\section{The KDM6 subfamily}

KDM6 subfamily members catalyze H3K27me3/me2 demethylation. This family includes UTX, JMJD3, and UTY proteins, although HDM activity has not been shown for UTY (Agger, et al. 2007, De Santa, et al. 2007, Lan, et al. 2007, Lee, et al. 2007b).

As described above, the H3K27 methylation status is essential for cell fate determination in stem cells. Accordingly, H3K27me3/me2 HDMs are involved in important aspects of neural development. Several studies have demonstrated that JMJD3 (unlike UTX) is highly regulated at the transcriptional level in response to different developmental, differentiation, and stress-related signals. In a developmental context, Jmjd3 was up-regulated during differentiation of ESCs to a neural lineage, and it was required for neuronal commitment (Burgold, et al. 2008). Besides, overexpression of $J m j d 3$ in NPCs induced the expression of various neuronal genes in a HDM activity-dependent manner (Jepsen, et al., 2007). Moreover, it has been described a direct relation between JMJD3 and the corepressor SMRT (silencing mediator of retinoic acid and thyroid hormone receptor) that is essential for proper forebrain development. SMRT is necessary to maintain the NSC state, mediating the retinoicacid- and Notch-dependent transcriptional response. In isolated NPCs, SMRT prevented retinoic-acid-receptor-dependent induction of neuronal differentiation in the absence of any ligand by repressing $J m j d 3$, which in turn participates in the activation of the neurogenic program (Fig. 2). Mechanistically, JMJD3 has been shown to cooperate with 
a number of different signals during neural development. (i) In P19 cells, in response to retinoic acid (RA), JMJD3 was recruited by the Hes1 transcription factor to the Mash1 promoter to facilitate efficient expression of the Mash1 gene and to drive RA-induced neuronal differentiation (Dai, et al. 2010). (ii) In vivo experiments in the chick neural tube have demonstrated that TGF $\beta$-induced neuronal differentiation was dependent on JMJD3 HDM activity (Estarás, et al. 2012). Moreover, in neural stem cells (NSCs), upon signaling activation, SMAD3 recruited JMJD3 to the promoter of TGF $\beta$ responsive genes to facilitate transcription elongation, which allowed the TGF $\beta$ developmental program to proceed (Estarás, et al. 2012, Estarás, et al. 2013) (Fig. 3). (iii) In response to BMP pathway activation, JMJD3 interacted with SMAD1/SMAD4 to demethylate and activate the NOGGIN promoter during spinal cord development. At the same time, NOGGIN antagonized the BMP pathway, generating a negativefeedback regulatory loop, which controlled the dorsal interneuron generation mediated by JMJD3 HDM activity (Akizu, et al. 2010). These data point to JMJD3 as a critical integrator of neural developmental cues. Accordingly, a knockout of the mouse Jmjd3 caused perinatal lethality due to an immature respiratory neuronal network (Burgold, et al. 2012). Furthermore, JMJD3 was shown to be essential for M2 microglia polarization. Suppressing Jmjd3 in N9 microglia led to the inhibition of M2 polarization, an increase in M1 microglial inflammatory responses, and induction of neuronal death in vitro (Tang, et al. 2014).

These data suggested that JMJD3 is the member of the KDM6 subfamily that plays a central role in regulating $\mathrm{H} 3 \mathrm{~K} 27 \mathrm{me} 3 / \mathrm{me} 2$ levels in neural genes. Nevertheless, UTX has also been reported to play a functional role in neural development. Incorporation of UTX, but not JMJD3, into the $H O X$ gene regions was required for RAinduced neural differentiation in hESCs (Shahhoseini, et al. 2013). 
Several reports have suggested that non-histone proteins can also be targeted and regulated by both HMT and HDM enzymes (Huang, et al. 2007). Recent data have indicated that JMJC-mediated demethylation of non-histone substrates might contribute to neural differentiation. The interaction between JMJD3 and p53 during mouse NSC differentiation resulted in nuclear accumulation of p53 (Sola, et al. 2011). Another member of the p53 family, p63 (TAp63g), is a direct target of JMJD3 HDM activity. Through demethylation, JMJD3 stabilizes p63 and influences its cellular distribution to promote the correct expression of p63-regulated neural-specific genes (Fonseca, et al. 2012).

\section{The KDM7 subfamily}

The KDM7 subfamily, also called PHF (plant homeodomain finger), is the most recently identified HDM subfamily. In mammals, it consists of three proteins: KIAA1718 which targets H3K9me2/me1 and H3K27me2/1 (Horton, et al. 2010, Huang, et al. 2010b, Tsukada, et al. 2010); PHF8, which demethylates H3K9me2/me1 and H4K20me1 (Horton, et al. 2010, Liu, et al. 2010, Loenarz, et al. 2010, Qi, et al. 2010); and PHF2, which targets H3K9me2/me1 and H4K20me3 (Wen, et al. 2010, Baba, et al. 2011, Stender, et al. 2012, ).

PHF8 is the best-known member of the subfamily, partly because PHF8 mutations have been found in patients with XLMR or cleft lip/palate (Laumonnier, et al. 2005, Abidi, et al. 2007, Koivisto, et al. 2007). Interestingly, many of these mutations impair the HDM catalytic activity (Loenarz, et al. 2010, Qiu, et al. 2010, Yu, et al. 2010). How mutations on PHF8 lead to XLMR remains unclear. Many studies have implicated PHF8 in the regulation of XLMR-related genes, including JARIDIC (see 
above). Moreover, PHF8 associates with a zinc finger protein that is related to XLMR, ZNF11 (Kleine-Kohlbrecher, et al. 2010). Recent data demonstrated that PHF8 HDM activity was essential for promoting cytoskeleton dynamics, and it was required for proper neurite outgrowth in mouse primary cortical neurons (Asensio-Juan, et al. 2012). Consistent with those findings, depletion of the zebrafish $P H F$ homolog led to a decrease in tectum size, a loss of neurons, and craniofacial alterations (Qi, et al. 2010, Tsukada, et al. 2010). Although PHF8 is the most studied member of the KDM7 subfamily, another HDM of this subfamily has been associated with neural development. When KIAA1718 was knocked down, neural differentiation was blocked in mouse ESCs. This proneural effect was due to the direct transcriptional activation of FGF4, a signaling component implicated in neural differentiation (Huang, et al. 2010b). In addition, KIAA1718 promoted neural induction in early chick embryos; its overexpression led to an expansion of the neural plate (Huang, et al. 2010a).

\section{The HDM2/3/4 subfamilies}

Although not so many data support a definite role for the KDM2, KDM3, or KDM4 subfamilies in neural development, we will point to some studies that reveal their importance in such a context. JMJD1C, a member of the KDM3 subfamily, that targets H3K9me2/me1 (Yamane, et al. 2006, Kim, et al. 2010, Kim, et al. 2012), has been recently shown to repress neural differentiation. JMJD1C binds and demethylates miR-302 promoter to induce miR-302 expression, which prevents neural induction (Wang, et al. 2014). The mammalian KDM4A subfamily includes four members: KDM4A (Klose, et al. 2006, Whetstine, et al. 2006, Trojer, et al. 2009), KDM4B (Fodor, et al. 2006, Whetstine, et al. 2006, Trojer, et al. 2009), KDM4C (Cloos, et al. 
2006, Whetstine, et al. 2006, Trojer, et al. 2009) and KDM4D (Whetstine, et al. 2006, Shin and Janknecht, 2007, Trojer, et al. 2009). Interestingly, it was recently shown that KDM4A drives neural crest specification in the chick embryo; loss of KDM4 leads to a down-regulation of neural crest specifier genes due to demethylation of regulatory regions (Strobl-Mazzulla, et al. 2010). The KDM2 subfamily, which targets H3K36me2/me1 (Tsukada, et al. 2006, He, et al. 2008, Lagarou, et al. 2008) and H3K4me3 (Frescas, et al. 2007) was reported to be involved mainly in oncogenesis (Suzuki, et al. 2006, Pfau, et al. 2008).

\section{Role of jumonji family in neurodevelopmental diseases}

As described in the Introduction, histone methylation/demethylation equilibrium plays an essential role in development, particularly during neural development. Thus, it is not surprising that specific alterations in HMT and HDM activities correlate with neurodevelopmental disorders (Table 2). For example, changes in HDM activity, due to mutations in JARIDIC and PHF8, have been linked to mental retardation and facial morphological alterations in humans. A close analysis of the Jarid1C expression pattern in mice indicated that it was highly expressed in the hippocampus, which points to a role in cognition. Moreover, studies performed in different animal models have demonstrated that JARID1C is involved in neuronal survival and dendritic development (Iwase, et al. 2007). Similarly, PHF8 HDM activity is required for neurite outgrowth (Asensio-Juan, et al. 2012). Thus, the XLMR associated with PHF8 mutations might be due to deficient neuronal network establishment during development. Interestingly, the genes that encode JARIDIC and PHF8 are located on the $\mathrm{X}$ chromosome, where the genes that regulate cognitive functions are more represented than in autosomes 
(Pattaroni and Jacob, 2013). Taken together, these data provide new insights into XLMR in humans, and they hint that HDM activity plays a critical role.

Other developmental diseases that have been directly or indirectly related to alterations in HDM activity include: (i) the Kabuki syndrome, which causes developmental delay and congenital anomalies; it has been recently associated with a deletion of the UTX gene (Lederer, et al. 2012); (ii) autism spectrum disorders (ASD) have been related with alterations in the activity of at least two HDMs: JARID1C (Adegbola, et al. 2008) and JMJD2C (Kantojarvi, et al. 2010).

Finally, several reports have suggested that JMJD3, UTX, and KDM2B HDMs might play critical roles in cranial neural tube development (Cox, et al. 2010, Fukuda, et al. 2011, Tsurubuchi, et al. 2013). For example, $K d m 2 B$-deficient mice exhibited failure of neural tube closure, which led to exencephaly (Fukuda, et al. 2011). In addition, decreased levels of JMJD3 were found in the amniotic fluid and serum of pregnant women with neural tube defect-affected embryos (Tsurubuchi, et al. 2013). These data have opened the possibility that these HDMs, or their enzymatic activities, may serve as potential therapeutic targets and as biomarkers for associated conditions.

\section{Conclusions and future perspectives}

During neural development, a complex regulatory network controls transcriptional programs. In the last decade, HDMs have been identified as key components of this network (Fig. 4). In addition to methylation, other modifications on histones can fine-tune transcriptional activity at each developmental stage. Consequently, many HDMs and HMTs are found in multiprotein complexes that 
Fueyo et al.

contain other histone-modifying activities that coordinate the establishment of the final epigenetic landscape.

Although enormous progress has been made in the last few years in understanding the regulatory mechanisms that control the activity of HDMs, many questions remain open. It is particularly important to clarify how HDMs find their appropriate target genes in each different developmental context. HDMs act in coordination with intrinsic transcriptional programs and extrinsic signals. Thus, we speculate that direct interactions with transcription factors and the responses to developmental signals will determine how HDMs are recruited to specific sets of genes to provide a time- and space-appropriate response. How extrinsic signals control HDM activity remains an unanswered question. Developmental cues might affect their association with other histone-modifying enzymes, with transcription factors, or with other cellular components. In addition, extrinsic signals may directly modify the HDMs to alter their enzymatic activity, their stability, or their cellular localization.

Another unresolved question is: what is the cellular role of HDMs? Many data in the literature indicate that, although they contribute to transcriptional control, they do not play an instructive role during gene transcription; instead, they modulate the response to fine-tune the transcriptional output. The importance of non-histone substrate demethylation could also be relevant in HDM modulation of transcription. Moreover, many studies have confirmed that several HDMs play a role that is independent of HDM activity (Koyama-Nasu, et al. 2007, Secombe, et al. 2007, Lagarou, et al. 2008, Li, et al. 2008, Lee, et al. 2009, Miller, et al. 2010, DiTacchio, et al. 2011, Landeira and Fisher, 2011, Shpargel, et al. 2012). Experiments that address the role of HDM activity are essential for fully understanding the contribution of these enzymes to cellular responses. 
To comprehend the role of HDMs, it will be important to characterize dynamic changes in genome-wide histone modification patterns and changes in their specific targets during development. Finally, the generation of more animal models to analyze in vivo functions at different developmental stages will be crucial for understanding the role of these enzymes in neural development and in neurodevelopmental diseases.

\section{Acknowledgments}

We would like to acknowledge the contributions of the researchers in this field, which could not be cited here, due space limitations. This work was supported by grants (BFU2009-11527, BFU-2012-34261) from the Spanish MINECO, a grant (090210) from the Fundaciò La Marató de TV3, and a grant from the Fondation Jérôme Lejeune. AG received a FPU fellowship.

\section{Figure Legends}

Fig. 1 Function of JARID1B in mouse neural development. a JARID1B maintains the low levels of $\mathrm{H} 3 \mathrm{~K} 4 \mathrm{me} 3$ that are needed to repress key neural development genes, such as Pax6 and Otx2. b In Jarid1b KO embryos, H3K4me3 levels are increased, and a high neonatal lethality is observed together with several neurodevelopmental defects (Albert et al. 2013). Red arrows mean gene silencing, green arrows depict transcription activation

Fig. 2 SMRT repression of retinoic acid-dependent JMJD3 expression avoids neuronal differentiation. a SMRT blocks the expression of JMJD3 by counteracting its retinoic 
Fueyo et al.

acid-dependent activation. As a consequence, $\mathrm{H} 3 \mathrm{~K} 27 \mathrm{me} 3$ at $D l x 5$ promoter is not removed, the gene remains silent, and the NSC state is maintained. b In SMRT KO mice retinoic acid receptor (RAR) binds to the retinoic acid responsive element (RARE) and promotes Jmjd3 transcription activation. Demethylation by JMJD3 causes Dlx5 gene induction and NSC differentiation into neurons (Jepsen et al. 2007). Red arrows mean gene silencing, green arrows depict transcription activation

Fig. 3 JMJD3 cooperates with TGF $\beta$ signaling to induce expression of the neurogenic gene Neurog2. a In the absence of the signal, Neurog2 remains silent due to the high levels of H3K27me3 on its promoter and coding region. b Upon TGF $\beta$ stimulation SMAD3 is recruited to the Neurog2 promoter and targets JMJD3 to this region. c JMJD3 interacts with RNA polymerase II phosphorylated in serine 2 and promotes transcription elongation by demethylating the gene body (Estaras et al. 2012, Estaras et al. 2013). Red arrows mean gene silencing, green arrows depict transcription activation (small arrowhead: initiation, big arrowhead: high expression)

Fig. 4 JMJC histone demethylases are essential for progression from ESCs to terminal differentiated neurons. In ESCs, JMJD1C is necessary to maintain the stem cell state, while JARID1C, UTX, JMJD3 and KIAA1718 are required to promote neural commitment and differentiation from ESCs to NSCs. In addition, JMJD3 is fundamental to induce neurodifferentiation from NSCs, collaborating with RA, TGF $\beta$ and BMP pathways. Finally, the HDMs JARID1C and PHF8 contribute to the correct development and maintenance of axons and dendrites in mature neurons

\section{References}


Abidi FE, Miano MG, Murray JC, Schwartz CE (2007) A novel mutation in the PHF8 gene is associated with X-linked mental retardation with cleft lip/cleft palate. Clin Genet 72:19-22

Adegbola A, Gao H, Sommer S, Browning M (2008) A novel mutation in JARID1C/SMCX in a patient with autism spectrum disorder (ASD). Am J Med Genet A 146A:505-511

Agger K, Cloos PA, Christensen J, Pasini D, Rose S, Rappsilber J, Issaeva I, Canaani E, Salcini AE, Helin K (2007) UTX and JMJD3 are histone H3K27 demethylases involved in HOX gene regulation and development. Nature 449:731-734

Akizu N, Estaras C, Guerrero L, Marti E, Martinez-Balbas MA (2010) H3K27me3 regulates BMP activity in developing spinal cord. Development 137:2915-2925

Albert M, Schmitz SU, Kooistra SM, Malatesta M, Morales Torres C, Rekling JC, Johansen JV, Abarrategui I, Helin K (2013) The histone demethylase Jarid1b ensures faithful mouse development by protecting developmental genes from aberrant H3K4me3. PLoS Genet 9:e1003461

Asensio-Juan E, Gallego C, Martinez-Balbas MA (2012) The histone demethylase PHF8 is essential for cytoskeleton dynamics. Nucleic Acids Res 40:9429-9440

Azuara V, Perry P, Sauer S, Spivakov M, Jorgensen HF, John RM, Gouti M, Casanova M, Warnes G, Merkenschlager M, Fisher AG (2006) Chromatin signatures of pluripotent cell lines. Nat Cell Biol 8:532-538

Baba A, Ohtake F, Okuno Y, Yokota K, Okada M, Imai Y, Ni M, Meyer CA, Igarashi K, Kanno J, Brown M, Kato S (2011) PKA-dependent regulation of the histone lysine demethylase complex PHF2-ARID5B. Nat Cell Biol 13:668-675

Bannister AJ, Kouzarides T (2011) Regulation of chromatin by histone modifications. Cell Res 21:381-395

Bernstein BE, Mikkelsen TS, Xie X, Kamal M, Huebert DJ, Cuff J, Fry B, Meissner A, Wernig M, Plath K, Jaenisch R, Wagschal A, Feil R, Schreiber SL, Lander ES (2006) A bivalent chromatin structure marks key developmental genes in embryonic stem cells. Cell 125:315-326

Boyer LA, Plath K, Zeitlinger J, Brambrink T, Medeiros LA, Lee TI, Levine SS, Wernig M, Tajonar A, Ray MK, Bell GW, Otte AP, Vidal M, Gifford DK, Young RA, Jaenisch R (2006) Polycomb complexes repress developmental regulators in murine embryonic stem cells. Nature 441:349-353

Bracken AP, Dietrich N, Pasini D, Hansen KH, Helin K (2006) Genome-wide mapping of Polycomb target genes unravels their roles in cell fate transitions. Genes Dev 20:1123-1136

Burgold T, Spreafico F, De Santa F, Totaro MG, Prosperini E, Natoli G, Testa G (2008) The histone H3 lysine 27-specific demethylase Jmjd3 is required for neural commitment. PLoS One 3:e3034

Burgold T, Voituron N, Caganova M, Tripathi PP, Menuet C, Tusi BK, Spreafico F, Bevengut M, Gestreau C, Buontempo S, Simeone A, Kruidenier L, Natoli G, Casola S, Hilaire G, Testa G (2012) The H3K27 demethylase JMJD3 is required for maintenance of the embryonic respiratory neuronal network, neonatal breathing, and survival. Cell Rep 2:1244-1258

Christensen J, Agger K, Cloos PA, Pasini D, Rose S, Sennels L, Rappsilber J, Hansen $\mathrm{KH}$, Salcini AE, Helin K (2007) RBP2 belongs to a family of demethylases, specific for tri-and dimethylated lysine 4 on histone 3. Cell 128:1063-1076

Ciccone DN, Su H, Hevi S, Gay F, Lei H, Bajko J, Xu G, Li E, Chen T (2009) KDM1B is a histone $\mathrm{H} 3 \mathrm{~K} 4$ demethylase required to establish maternal genomic imprints. Nature 461:415-418 
Cloos PA, Christensen J, Agger K, Maiolica A, Rappsilber J, Antal T, Hansen KH, Helin K (2006) The putative oncogene GASC1 demethylates tri- and dimethylated lysine 9 on histone H3. Nature 442:307-311

Cox BJ, Vollmer M, Tamplin O, Lu M, Biechele S, Gertsenstein M, van Campenhout C, Floss T, Kuhn R, Wurst W, Lickert H, Rossant J (2010) Phenotypic annotation of the mouse X chromosome. Genome Res 20:1154-1164

Dai JP, Lu JY, Zhang Y, Shen YF (2010) Jmjd3 activates Mash1 gene in RA-induced neuronal differentiation of P19 cells. J Cell Biochem 110:1457-1463

de la Cruz X, Lois S, Sanchez-Molina S, Martinez-Balbas MA (2005) Do protein motifs read the histone code? Bioessays 27:164-175

De Santa F, Totaro MG, Prosperini E, Notarbartolo S, Testa G, Natoli G (2007) The histone H3 lysine-27 demethylase Jmjd3 links inflammation to inhibition of polycomb-mediated gene silencing. Cell 130:1083-1094

Dey BK, Stalker L, Schnerch A, Bhatia M, Taylor-Papidimitriou J, Wynder C (2008) The histone demethylase KDM5b/JARID1b plays a role in cell fate decisions by blocking terminal differentiation. Mol Cell Biol 28:5312-5327

DiTacchio L, Le HD, Vollmers C, Hatori M, Witcher M, Secombe J, Panda S (2011) Histone lysine demethylase JARID1a activates CLOCK-BMAL1 and influences the circadian clock. Science 333:1881-1885

Estaras C, Akizu N, Garcia A, Beltran S, de la Cruz X, Martinez-Balbas MA (2012) Genome-wide analysis reveals that Smad3 and JMJD3 HDM co-activate the neural developmental program. Development 139:2681-2691

Estaras C, Fueyo R, Akizu N, Beltran S, Martinez-Balbas MA (2013) RNA polymerase II progression through H3K27me3-enriched gene bodies requires JMJD3 histone demethylase. Mol Biol Cell 24:351-360

Fodor BD, Kubicek S, Yonezawa M, O'Sullivan RJ, Sengupta R, Perez-Burgos L, Opravil S, Mechtler K, Schotta G, Jenuwein T (2006) Jmjd2b antagonizes H3K9 trimethylation at pericentric heterochromatin in mammalian cells. Genes Dev 20:1557-1562

Fonseca MB, Nunes AF, Morgado AL, Sola S, Rodrigues CM (2012) TAp63gamma demethylation regulates protein stability and cellular distribution during neural stem cell differentiation. PLoS One 7:e52417

Frescas D, Guardavaccaro D, Bassermann F, Koyama-Nasu R, Pagano M (2007) JHDM1B/FBXL10 is a nucleolar protein that represses transcription of ribosomal RNA genes. Nature 450:309-313

Fukuda T, Tokunaga A, Sakamoto R, Yoshida N (2011) Fbxl10/Kdm2b deficiency accelerates neural progenitor cell death and leads to exencephaly. Mol Cell Neurosci 46:614-624

Guillemot F (2005) Cellular and molecular control of neurogenesis in the mammalian telencephalon. Curr Opin Cell Biol 17:639-647

Guillemot F (2007) Cell fate specification in the mammalian telencephalon. Prog Neurobiol 83:37-52

He J, Kallin EM, Tsukada Y, Zhang Y (2008) The H3K36 demethylase Jhdm1b/Kdm2b regulates cell proliferation and senescence through p15(Ink4b). Nat Struct Mol Biol 15:1169-1175

Hirabayashi Y, Suzki N, Tsuboi M, Endo TA, Toyoda T, Shinga J, Koseki H, Vidal M, Gotoh Y (2009) Polycomb limits the neurogenic competence of neural precursor cells to promote astrogenic fate transition. Neuron 63:600-613 
Horton JR, Upadhyay AK, Qi HH, Zhang X, Shi Y, Cheng X (2010) Enzymatic and structural insights for substrate specificity of a family of jumonji histone lysine demethylases. Nat Struct Mol Biol 17:38-43

Huang C, Chen J, Zhang T, Zhu Q, Xiang Y, Chen CD, Jing N (2010a) The dual histone demethylase KDM7A promotes neural induction in early chick embryos. Dev Dyn 239:3350-3357

Huang C, Xiang Y, Wang Y, Li X, Xu L, Zhu Z, Zhang T, Zhu Q, Zhang K, Jing N, Chen CD (2010b) Dual-specificity histone demethylase KIAA1718 (KDM7A) regulates neural differentiation through FGF4. Cell Res 20:154-165

Huang J, Sengupta R, Espejo AB, Lee MG, Dorsey JA, Richter M, Opravil S, Shiekhattar R, Bedford MT, Jenuwein T, Berger SL (2007) p53 is regulated by the lysine demethylase LSD1. Nature 449:105-108

Iwase S, Lan F, Bayliss P, de la Torre-Ubieta L, Huarte M, Qi HH, Whetstine JR, Bonni A, Roberts TM, Shi Y (2007) The X-linked mental retardation gene SMCX/JARID1C defines a family of histone H3 lysine 4 demethylases. Cell 128:1077-1088

Jensen LR, Amende M, Gurok U, Moser B, Gimmel V, Tzschach A, Janecke AR, Tariverdian G, Chelly J, Fryns JP, Van Esch H, Kleefstra T, Hamel B, Moraine C, Gecz J, Turner G, Reinhardt R, Kalscheuer VM, Ropers HH, Lenzner S (2005) Mutations in the JARID1C gene, which is involved in transcriptional regulation and chromatin remodeling, cause X-linked mental retardation. Am J Hum Genet 76:227-236

Jensen LR, Bartenschlager H, Rujirabanjerd S, Tzschach A, Numann A, Janecke AR, Sporle R, Stricker S, Raynaud M, Nelson J, Hackett A, Fryns JP, Chelly J, de Brouwer AP, Hamel B, Gecz J, Ropers HH, Kuss AW (2010) A distinctive gene expression fingerprint in mentally retarded male patients reflects disease-causing defects in the histone demethylase KDM5C. Pathogenetics 3:2

Jepsen K, Solum D, Zhou T, McEvilly RJ, Kim HJ, Glass CK, Hermanson O, Rosenfeld MG (2007) SMRT-mediated repression of an H3K27 demethylase in progression from neural stem cell to neuron. Nature 450:415-419

Kantojarvi K, Onkamo P, Vanhala R, Alen R, Hedman M, Sajantila A, Nieminen-von Wendt T, Jarvela I (2010) Analysis of 9p24 and 11p12-13 regions in autism spectrum disorders: rs 1340513 in the JMJD2C gene is associated with ASDs in Finnish sample. Psychiatr Genet 20:102-108

Kim JY, Kim KB, Eom GH, Choe N, Kee HJ, Son HJ, Oh ST, Kim DW, Pak JH, Baek HJ, Kook H, Hahn Y, Chakravarti D, Seo SB (2012) KDM3B is the H3K9 demethylase involved in transcriptional activation of $1 \mathrm{mo} 2$ in leukemia. Mol Cell Biol 32:2917-2933

Kim SM, Kim JY, Choe NW, Cho IH, Kim JR, Kim DW, Seol JE, Lee SE, Kook H, Nam KI, Bhak YY, Seo SB (2010) Regulation of mouse steroidogenesis by WHISTLE and JMJD1C through histone methylation balance. Nucleic Acids Res 38:6389-6403

Kleine-Kohlbrecher D, Christensen J, Vandamme J, Abarrategui I, Bak M, Tommerup N, Shi X, Gozani O, Rappsilber J, Salcini AE, Helin K (2010) A functional link between the histone demethylase PHF8 and the transcription factor ZNF711 in X-linked mental retardation. Mol Cell 38:165-178

Klose RJ, Yamane K, Bae Y, Zhang D, Erdjument-Bromage H, Tempst P, Wong J, Zhang Y (2006) The transcriptional repressor JHDM3A demethylates trimethyl histone H3 lysine 9 and lysine 36. Nature 442:312-316 
Klose RJ, Yan Q, Tothova Z, Yamane K, Erdjument-Bromage H, Tempst P, Gilliland DG, Zhang Y, Kaelin WG, Jr. (2007) The retinoblastoma binding protein RBP2 is an H3K4 demethylase. Cell 128:889-900

Koivisto AM, Ala-Mello S, Lemmela S, Komu HA, Rautio J, Jarvela I (2007) Screening of mutations in the PHF8 gene and identification of a novel mutation in a Finnish family with XLMR and cleft lip/cleft palate. Clin Genet 72:145-149

Kooistra SM, Helin K (2012) Molecular mechanisms and potential functions of histone demethylases. Nat Rev Mol Cell Biol 13:297-311

Kouzarides T (2007) Chromatin modifications and their function. Cell 128:693-705

Koyama-Nasu R, David G, Tanese N (2007) The F-box protein Fbl10 is a novel transcriptional repressor of c-Jun. Nat Cell Biol 9:1074-1080

Lagarou A, Mohd-Sarip A, Moshkin YM, Chalkley GE, Bezstarosti K, Demmers JA, Verrijzer CP (2008) dKDM2 couples histone H2A ubiquitylation to histone H3 demethylation during Polycomb group silencing. Genes Dev 22:2799-2810

Lan F, Bayliss PE, Rinn JL, Whetstine JR, Wang JK, Chen S, Iwase S, Alpatov R, Issaeva I, Canaani E, Roberts TM, Chang HY, Shi Y (2007) A histone H3 lysine 27 demethylase regulates animal posterior development. Nature 449:689-694

Landeira D, Fisher AG (2011) Inactive yet indispensable: the tale of Jarid2. Trends Cell Biol 21:74-80

Laumonnier F, Holbert S, Ronce N, Faravelli F, Lenzner S, Schwartz CE, Lespinasse J, Van Esch H, Lacombe D, Goizet C, Phan-Dinh Tuy F, van Bokhoven H, Fryns JP, Chelly J, Ropers HH, Moraine C, Hamel BC, Briault S (2005) Mutations in PHF8 are associated with $\mathrm{X}$ linked mental retardation and cleft lip/cleft palate. $\mathrm{J}$ Med Genet 42:780-786

Lederer D, Grisart B, Digilio MC, Benoit V, Crespin M, Ghariani SC, Maystadt I, Dallapiccola B, Verellen-Dumoulin C (2012) Deletion of KDM6A, a histone demethylase interacting with MLL2, in three patients with Kabuki syndrome. Am J Hum Genet 90:119-124

Lee MG, Norman J, Shilatifard A, Shiekhattar R (2007a) Physical and functional association of a trimethyl H3K4 demethylase and Ring6a/MBLR, a polycomblike protein. Cell 128:877-887

Lee MG, Villa R, Trojer P, Norman J, Yan KP, Reinberg D, Di Croce L, Shiekhattar R (2007b) Demethylation of H3K27 regulates polycomb recruitment and H2A ubiquitination. Science 318:447-450

Lee N, Erdjument-Bromage H, Tempst P, Jones RS, Zhang Y (2009) The H3K4 demethylase lid associates with and inhibits histone deacetylase Rpd3. Mol Cell Biol 29:1401-1410

Lee S, Lee SK (2010) Crucial roles of histone-modifying enzymes in mediating neural cell-type specification. Curr Opin Neurobiol 20:29-36

Lee SK, Pfaff SL (2001) Transcriptional networks regulating neuronal identity in the developing spinal cord. Nat Neurosci 4 Suppl:1183-1191

Lee TI, Jenner RG, Boyer LA, Guenther MG, Levine SS, Kumar RM, Chevalier B, Johnstone SE, Cole MF, Isono K, Koseki H, Fuchikami T, Abe K, Murray HL, Zucker JP, Yuan B, Bell GW, Herbolsheimer E, Hannett NM, Sun K, Odom DT, Otte AP, Volkert TL, Bartel DP, Melton DA, Gifford DK, Jaenisch R, Young RA (2006) Control of developmental regulators by Polycomb in human embryonic stem cells. Cell 125:301-313

Li F, Huarte M, Zaratiegui M, Vaughn MW, Shi Y, Martienssen R, Cande WZ (2008) $\mathrm{Lid} 2$ is required for coordinating $\mathrm{H} 3 \mathrm{~K} 4$ and $\mathrm{H} 3 \mathrm{~K} 9$ methylation of heterochromatin and euchromatin. Cell 135:272-283 
Liu W, Tanasa B, Tyurina OV, Zhou TY, Gassmann R, Liu WT, Ohgi KA, Benner C, Garcia-Bassets I, Aggarwal AK, Desai A, Dorrestein PC, Glass CK, Rosenfeld MG (2010) PHF8 mediates histone H4 lysine 20 demethylation events involved in cell cycle progression. Nature 466:508-512

Loenarz C, Ge W, Coleman ML, Rose NR, Cooper CD, Klose RJ, Ratcliffe PJ, Schofield CJ (2010) PHF8, a gene associated with cleft lip/palate and mental retardation, encodes for an Nepsilon-dimethyl lysine demethylase. Hum Mol Genet 19:217-222

Lois S, Akizu N, de Xaxars GM, Vazquez I, Martinez-Balbas M, de la Cruz X (2010) Characterization of structural variability sheds light on the specificity determinants of the interaction between effector domains and histone tails. Epigenetics 5:137-148

Luger K (2003) Structure and dynamic behavior of nucleosomes. Curr Opin Genet Dev 13:127-135

Metzger E, Wissmann M, Yin N, Muller JM, Schneider R, Peters AH, Gunther T, Buettner R, Schule R (2005) LSD1 demethylates repressive histone marks to promote androgen-receptor-dependent transcription. Nature 437:436-439

Miller SA, Mohn SE, Weinmann AS (2010) Jmjd3 and UTX play a demethylaseindependent role in chromatin remodeling to regulate T-box family memberdependent gene expression. Mol Cell 40:594-605

Pasini D, Cloos PA, Walfridsson J, Olsson L, Bukowski JP, Johansen JV, Bak M, Tommerup N, Rappsilber J, Helin K (2010) JARID2 regulates binding of the Polycomb repressive complex 2 to target genes in ES cells. Nature 464:306-310

Pasini D, Hansen KH, Christensen J, Agger K, Cloos PA, Helin K (2008) Coordinated regulation of transcriptional repression by the RBP2 H3K4 demethylase and Polycomb-Repressive Complex 2. Genes Dev 22:1345-1355

Pattaroni C, Jacob C (2013) Histone methylation in the nervous system: functions and dysfunctions. Mol Neurobiol 47:740-756

Pedersen MT, Helin K (2010) Histone demethylases in development and disease. Trends Cell Biol 20:662-671

Peng JC, Valouev A, Swigut T, Zhang J, Zhao Y, Sidow A, Wysocka J (2009) Jarid2/Jumonji coordinates control of PRC2 enzymatic activity and target gene occupancy in pluripotent cells. Cell 139:1290-1302

Pfau R, Tzatsos A, Kampranis SC, Serebrennikova OB, Bear SE, Tsichlis PN (2008) Members of a family of JmjC domain-containing oncoproteins immortalize embryonic fibroblasts via a JmjC domain-dependent process. Proc Natl Acad Sci U S A 105:1907-1912

Qi HH, Sarkissian M, Hu GQ, Wang Z, Bhattacharjee A, Gordon DB, Gonzales M, Lan F, Ongusaha PP, Huarte M, Yaghi NK, Lim H, Garcia BA, Brizuela L, Zhao K, Roberts TM, Shi Y (2010) Histone H4K20/H3K9 demethylase PHF8 regulates zebrafish brain and craniofacial development. Nature 466:503-507

Qiu J, Shi G, Jia Y, Li J, Wu M, Dong S, Wong J (2010) The X-linked mental retardation gene PHF8 is a histone demethylase involved in neuronal differentiation. Cell Res 20:908-918

Schmitz SU, Albert M, Malatesta M, Morey L, Johansen JV, Bak M, Tommerup N, Abarrategui I, Helin K (2011) Jarid1b targets genes regulating development and is involved in neural differentiation. EMBO J 30:4586-4600

Secombe J, Li L, Carlos L, Eisenman RN (2007) The Trithorax group protein Lid is a trimethyl histone $\mathrm{H} 3 \mathrm{~K} 4$ demethylase required for dMyc-induced cell growth. Genes Dev 21:537-551 
Shahhoseini M, Taghizadeh Z, Hatami M, Baharvand H (2013) Retinoic acid dependent histone 3 demethylation of the clustered HOX genes during neural differentiation of human embryonic stem cells. Biochem Cell Biol 91:116-122

Shen X, Kim W, Fujiwara Y, Simon MD, Liu Y, Mysliwiec MR, Yuan GC, Lee Y, Orkin SH (2009) Jumonji modulates polycomb activity and self-renewal versus differentiation of stem cells. Cell 139:1303-1314

Sher F, Rossler R, Brouwer N, Balasubramaniyan V, Boddeke E, Copray S (2008) Differentiation of neural stem cells into oligodendrocytes: involvement of the polycomb group protein Ezh2. Stem Cells 26:2875-2883

Shi Y, Lan F, Matson C, Mulligan P, Whetstine JR, Cole PA, Casero RA (2004) Histone demethylation mediated by the nuclear amine oxidase homolog LSD1. Cell 119:941-953

Shin S, Janknecht R (2007) Activation of androgen receptor by histone demethylases JMJD2A and JMJD2D. Biochem Biophys Res Commun 359:742-746

Shpargel KB, Sengoku T, Yokoyama S, Magnuson T (2012) UTX and UTY demonstrate histone demethylase-independent function in mouse embryonic development. PLoS Genet 8:e1002964

Sola S, Xavier JM, Santos DM, Aranha MM, Morgado AL, Jepsen K, Rodrigues CM (2011) p53 interaction with JMJD3 results in its nuclear distribution during mouse neural stem cell differentiation. PLoS One 6:e18421

Song MR, Ghosh A (2004) FGF2-induced chromatin remodeling regulates CNTFmediated gene expression and astrocyte differentiation. Nat Neurosci 7:229-235

Stender JD, Pascual G, Liu W, Kaikkonen MU, Do K, Spann NJ, Boutros M, Perrimon N, Rosenfeld MG, Glass CK (2012) Control of proinflammatory gene programs by regulated trimethylation and demethylation of histone H4K20. Mol Cell 48:28-38

Strobl-Mazzulla PH, Sauka-Spengler T, Bronner-Fraser M (2010) Histone demethylase JmjD2A regulates neural crest specification. Dev Cell 19:460-468

Suzuki T, Minehata K, Akagi K, Jenkins NA, Copeland NG (2006) Tumor suppressor gene identification using retroviral insertional mutagenesis in Blm-deficient mice. EMBO J 25:3422-3431

Tahiliani M, Mei P, Fang R, Leonor T, Rutenberg M, Shimizu F, Li J, Rao A, Shi Y (2007) The histone H3K4 demethylase SMCX links REST target genes to Xlinked mental retardation. Nature 447:601-605

Tang Y, Li T, Li J, Yang J, Liu H, Zhang XJ, Le W (2014) Jmjd3 is essential for the epigenetic modulation of microglia phenotypes in the immune pathogenesis of Parkinson's disease. Cell Death Differ 21:369-380

Taverna SD, Li H, Ruthenburg AJ, Allis CD, Patel DJ (2007) How chromatin-binding modules interpret histone modifications: lessons from professional pocket pickers. Nat Struct Mol Biol 14:1025-1040

Trojer P, Zhang J, Yonezawa M, Schmidt A, Zheng H, Jenuwein T, Reinberg D (2009) Dynamic Histone H1 Isotype 4 Methylation and Demethylation by Histone Lysine Methyltransferase G9a/KMT1C and the Jumonji Domain-containing JMJD2/KDM4 Proteins. J Biol Chem 284:8395-8405

Tsukada Y, Fang J, Erdjument-Bromage H, Warren ME, Borchers CH, Tempst P, Zhang Y (2006) Histone demethylation by a family of JmjC domain-containing proteins. Nature 439:811-816

Tsukada Y, Ishitani T, Nakayama KI (2010) KDM7 is a dual demethylase for histone H3 Lys 9 and Lys 27 and functions in brain development. Genes Dev 24:432437 
Tsurubuchi T, Ichi S, Shim KW, Norkett W, Allender E, Mania-Farnell B, Tomita T, McLone DG, Ginsberg N, Mayanil CS (2013) Amniotic fluid and serum biomarkers from women with neural tube defect-affected pregnancies: a case study for myelomeningocele and anencephaly: clinical article. J Neurosurg Pediatr 12:380-389

Tzschach A, Lenzner S, Moser B, Reinhardt R, Chelly J, Fryns JP, Kleefstra T, Raynaud M, Turner G, Ropers HH, Kuss A, Jensen LR (2006) Novel JARID1C/SMCX mutations in patients with X-linked mental retardation. Hum Mutat 27:389

Wang J, Park JW, Drissi H, Wang X, Xu RH (2013) Epigenetic Regulation of miR-302 by JMJD1C Inhibits Neural Differentiation of Human Embryonic Stem Cells. J Biol Chem 289:2384-2395

Wen H, Li J, Song T, Lu M, Kan PY, Lee MG, Sha B, Shi X (2010) Recognition of histone H3K4 trimethylation by the plant homeodomain of PHF2 modulates histone demethylation. J Biol Chem 285:9322-9326

Whetstine JR, Nottke A, Lan F, Huarte M, Smolikov S, Chen Z, Spooner E, Li E, Zhang G, Colaiacovo M, Shi Y (2006) Reversal of histone lysine trimethylation by the JMJD2 family of histone demethylases. Cell 125:467-481

Yamane K, Tateishi K, Klose RJ, Fang J, Fabrizio LA, Erdjument-Bromage H, TaylorPapadimitriou J, Tempst P, Zhang Y (2007) PLU-1 is an H3K4 demethylase involved in transcriptional repression and breast cancer cell proliferation. Mol Cell 25:801-812

Yamane K, Toumazou C, Tsukada Y, Erdjument-Bromage H, Tempst P, Wong J, Zhang Y (2006) JHDM2A, a JmjC-containing H3K9 demethylase, facilitates transcription activation by androgen receptor. Cell 125:483-495

Yu L, Wang Y, Huang S, Wang J, Deng Z, Zhang Q, Wu W, Zhang X, Liu Z, Gong W, Chen Z (2010) Structural insights into a novel histone demethylase PHF8. Cell Res 20:166-173 
a

WT mice embryos

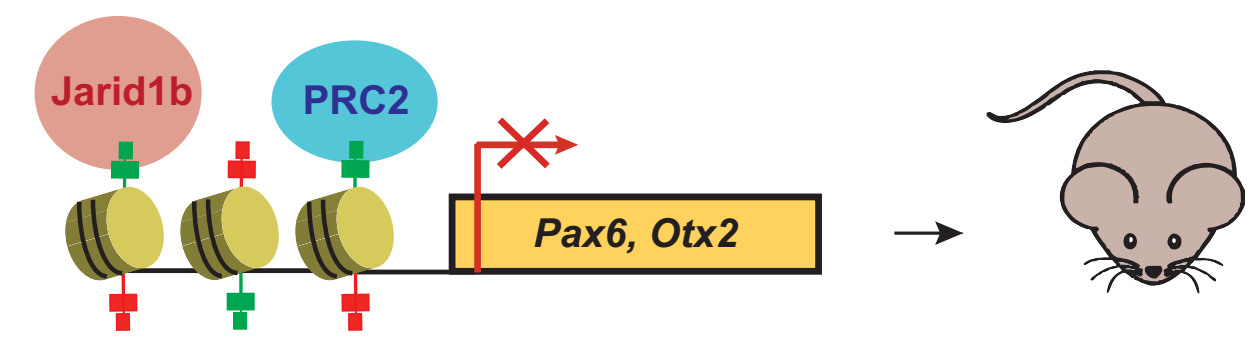

Proper neural development

b

Jarid1b KO mice embryos
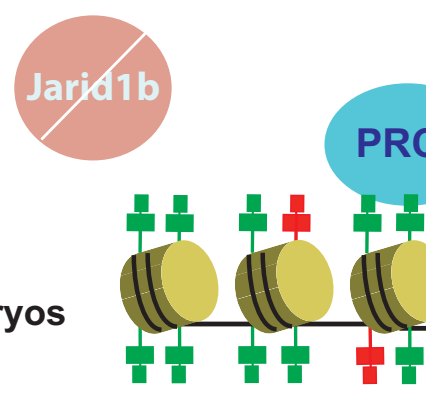

Pax6, Otx2

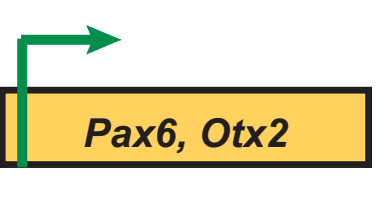

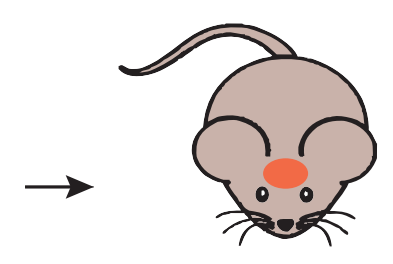

Neural development defects

TH3K4me3 T H3K27me3


a

WT mice embryos

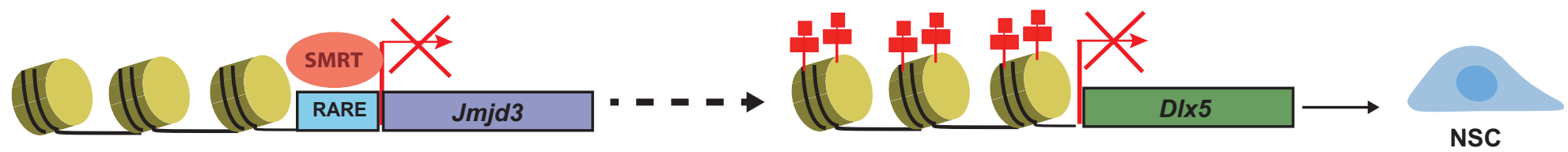

b

Smrt KO mice embryos

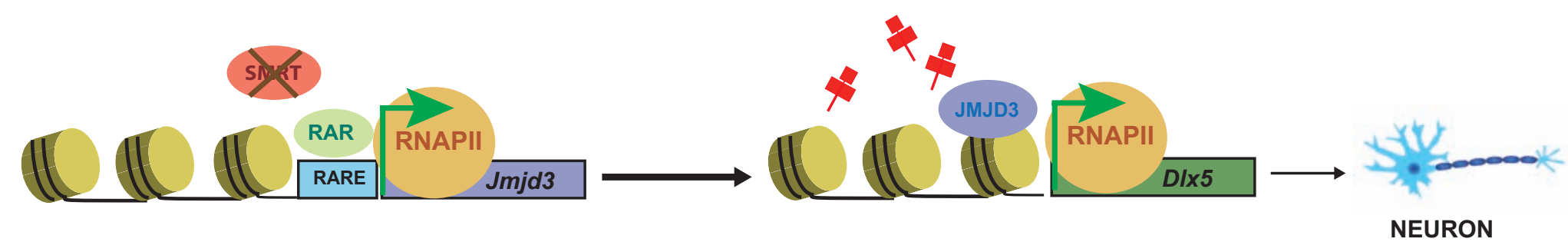

H3K27me3 
a
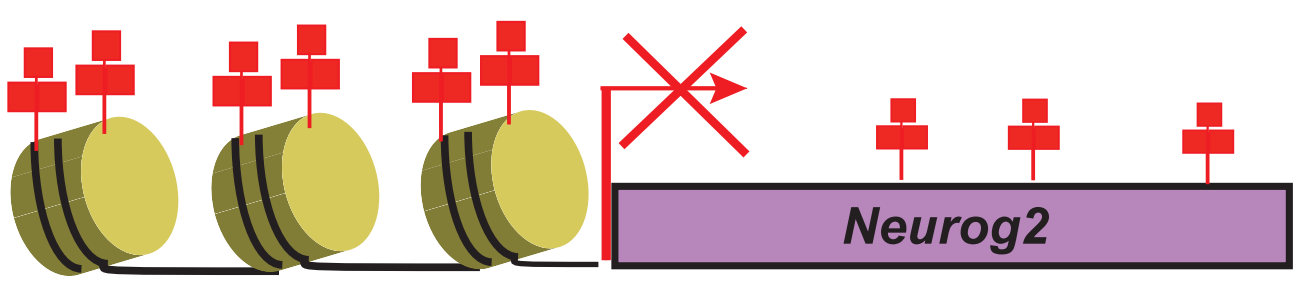

OFF

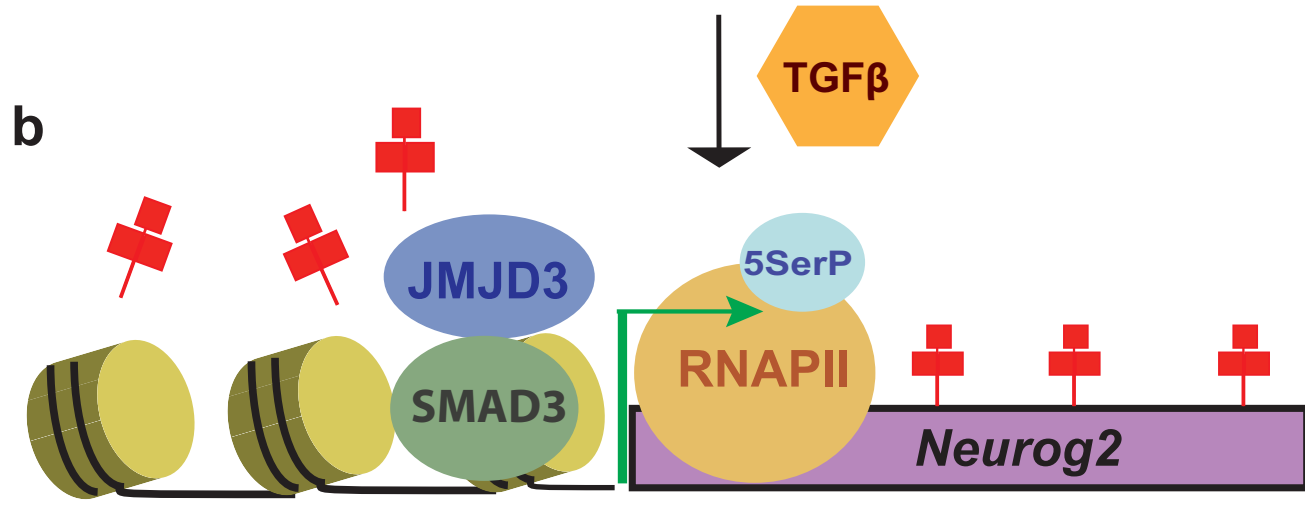

INITIATION

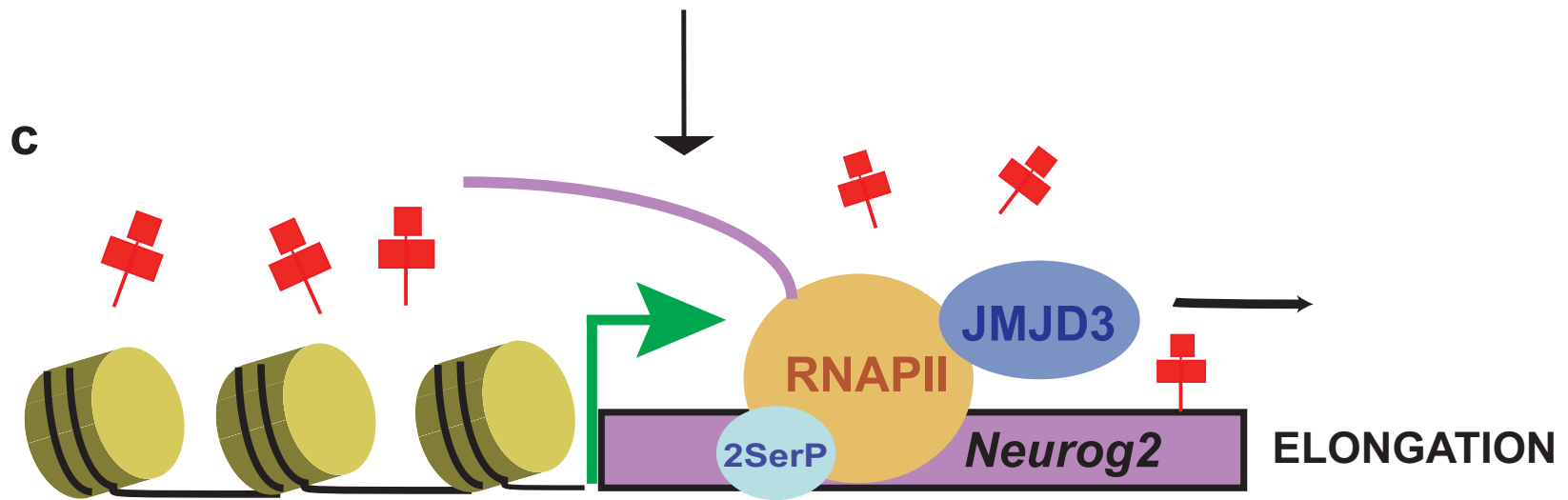

H3K27me3

2SerP phosphorylation in serine 2

5SerP phosphorylation in serine 5 


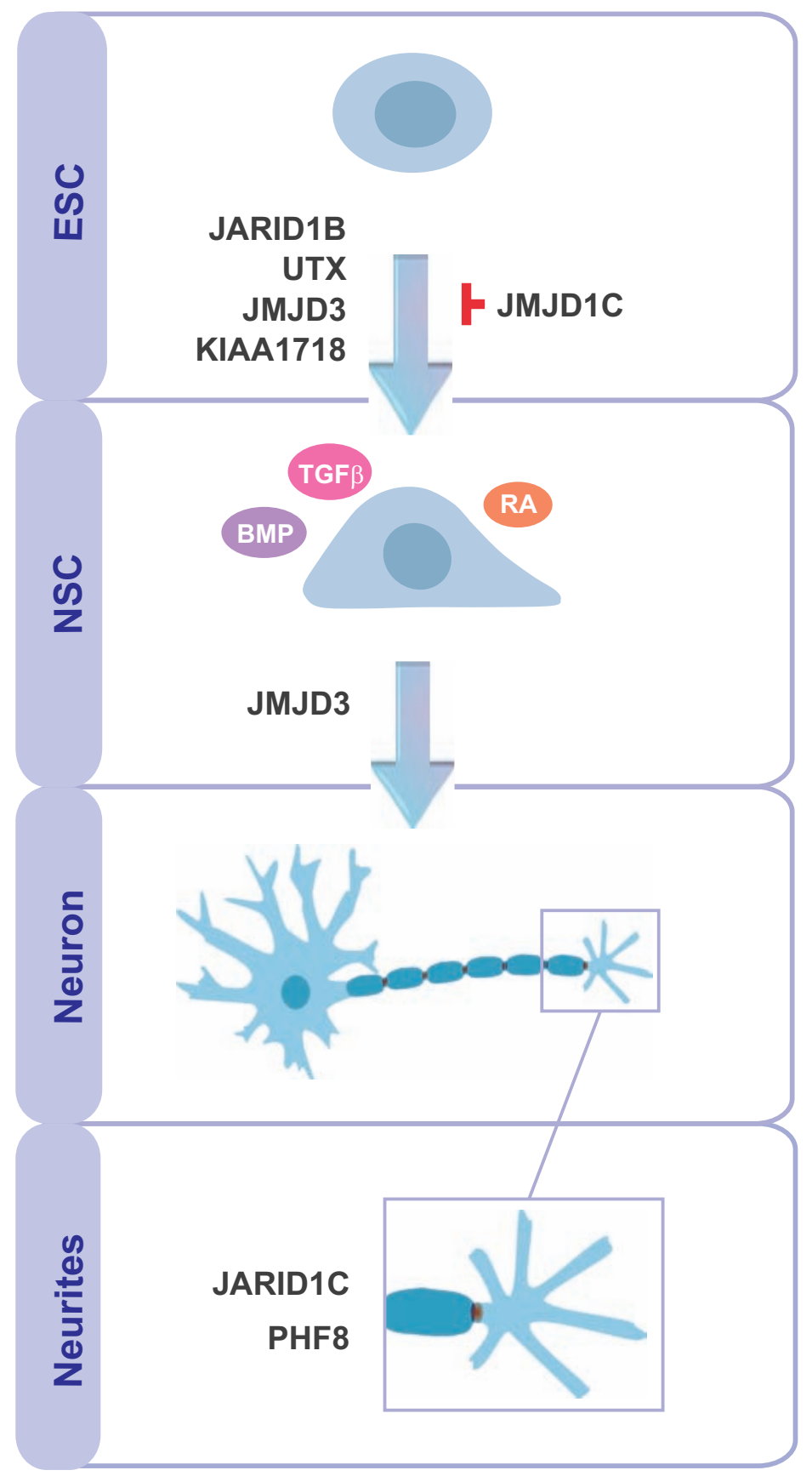




\begin{tabular}{|c|c|c|c|c|c|}
\hline FAMILY & HDM & OTHER NAMES & HISTONE SUBSTRATE & REFERENCES & RELATED HUMAN HMT \\
\hline \multirow{2}{*}{ LSD } & KDM1A & KDM1, KIAA0601, LSD1, AOF2 & $\mathrm{H} 3 \mathrm{~K} 4 \mathrm{me} 2 / \mathrm{me} 1, \mathrm{H} 3 \mathrm{~K} 9 \mathrm{me} 2 / \mathrm{me} 1$ & Shi et al. 2004, Metzger et al. 2005 & \multirow{2}{*}{$\begin{array}{l}\text { H3K4me 2/me1: SETD1A-B, KMT2A-D, KMT2E*; } \\
\text { H3K4me1: ASH1L, SEID7; H3K9me2: SUV39H1- } \\
\text { 2; H3K9me 2/me1: SETDB1, EHMT1-2, PRDM2. }\end{array}$} \\
\hline & KDM1B & LSD2, AOF1, C6orf193 & $\mathrm{H} 3 \mathrm{~K} 4 \mathrm{me} / \mathrm{me} 1, \mathrm{H} 3 \mathrm{~K} 9 \mathrm{me} 2 / \mathrm{me} 1$ & Ciccone et al. 2009 & \\
\hline \multirow{19}{*}{ JMJC } & KDM2A & JHDM1A, KIAA1004, CXXC8, FBL7, FBXL11 & H3K36me2/me1 & Tsukada et al. 2006 & \multirow{2}{*}{$\begin{array}{l}\text { H3K4me 3: KMT2A-D, SETD1A-B, SMYD3, ASH1L, } \\
\text { PRMD9; H3K36me2: SMYD2; H3K36me2/me1: } \\
\text { SETD2, SETMAR, NSD1-3, ASH1L. }\end{array}$} \\
\hline & KDM2B & JHDM1B, CXXC2, FBL10, FBXL10, PCCX2 & H3K4me3, H3K36me2 & Frescas et al. 2007, He et al. 2008 & \\
\hline & KDM $3 A$ & JHDM2A, JMJD1, JMJD1A, KIAA0742, TSGA & H3K9me2/me1 & Yamane et al. 2006 & \multirow{3}{*}{$\begin{array}{l}\text { H3K9me 2: SUV39H1-2; H3K9me 2/me 1: SETDB1, } \\
\text { EHMT1-2, PRDM2. }\end{array}$} \\
\hline & KDM3B & JHDM2B, JMJD1B, KIAA1082, C5orf7 & H3K9me2/me1 & Kim et al. 2012 & \\
\hline & JMJD1C & JHDM2C, KIAA1380, TRIP8 & H3K9me2/me1 & Kim et al. 2010 & \\
\hline & KDM4A & JHDM3A, JM.JD2A, KIAA0677 & H3К9me3/me2, Н3K36me3/me2, H1.4K26me3 & Whetstine et al. 2006, Klose et al. 2006, Trojer et al. 2009 & \multirow{4}{*}{$\begin{array}{l}\text { H3K9me 3: SETD2; H3K9me 3/me2: SUV39H1-2, } \\
\text { SEDBB1, PRDM2; H3K9me2: EHMT1-2; } \\
\text { H3K36me3/me2: SETD2, NSD1-3, ASH1L, SMYD2; } \\
\text { H3K36me2: SETMAR; H1.4K26me3/me2: EZH2, } \\
\text { EHMT1-2. }\end{array}$} \\
\hline & KDM4B & JHDM3B, JMJD2B, KIAA0876 & H3K9me3/me2, Н3K36me3/me2, H1.4K26me3 & Whetstine et al. 2006, Fodor et al. 2006, Trojer et al. 2009 & \\
\hline & KDM4C & JHDM3C, JMJD2C, KIAA0780, GASC1 & H3K9me3/me2, H3K36me3/me2, H1.4K26me3 & Whetstine et al. 2006, Cloos et al. 2006, Trojer et al. 2009 & \\
\hline & KDM4D & JHDM3D, JMJD2D, FLJ10251 & H3K9me3/me2, H1.4K26me3/me2 & Whetstine et al. 2006, Trojer et al. 2009 & \\
\hline & KDM5A & JARID1A, RBP2 & $\mathrm{H} 3 \mathrm{~K} 4 \mathrm{me} 3 / \mathrm{me} 2$ & Christensen et al. 2007, Klose et al. 2007 & \multirow{4}{*}{$\begin{array}{l}\text { H3K4me3: ASH1L, PRDM9; H3K4me3/me2: } \\
\text { KMT2A-D, SETD1A-B, SMYD3. }\end{array}$} \\
\hline & KDM5B & JARID1B, PLU1 & H3K4me3/me2 & Christensen et al. 2007 & \\
\hline & KDM5C & JARID1C, SMCX & H3K4me3/me2 & Christensen et al. 2007, Iw ase et al. 2007 & \\
\hline & KDM5D & JARID1D, SMCY & H3K4me3/me2 & Lee et al. 2007a & \\
\hline & KDM6A & UTX & H3K27me3/me2 & Agger et al. 2007, Lan et. Al 2007 & \multirow{3}{*}{ H3K27me3/me2: EZH1-2. } \\
\hline & KDM6B & JMJD3, KIAA0346 & H3K27me3/me2 & Agger et al. 2007, Lan et. Al 2007 & \\
\hline & UTY & & & & \\
\hline & KDM7A & JHDM1D, KIAA1718, KDM7 & H3K9me2/me1, H3K27me2/me1 & Tsukada et al. 2010, Horton et al. 2010, Huang et al. 2010b & \multirow{3}{*}{$\begin{array}{l}\text { H3K9me2: SUV39H1-2; H3K9me 2/me1: SETDB1, } \\
\text { EHMT1-2, PRDM2; H3K27me2/me1: EZH1-2; } \\
\text { H4K20me3: SMYD5, SUV42OH2; H4K20me1: } \\
\text { SETD8. }\end{array}$} \\
\hline & PHF8 & JHDM1F, KIAA1111, ZNF422 & H3K9me2/me1, H4K20me1 & Loenarz et al. 2010, Liu et al. 2010, Qi et al. 2010 & \\
\hline & PHF2 & JHDM1E, KIAA0662 & H3K9me2/me1, H4K20me3 & Wen et al. 2010, Baba et al. 2011, Stender et al. 2012 & \\
\hline
\end{tabular}


Table2. JMJC demethylases and their role in neural development and disease

HDM Function in Neural Development

KDM2B Embryonic neural tube development and neurulation in mice.

JMJD1C Inhibition of neural differentiation in hESC.

KDM4A Neural crest specification in chick embryo.

KDM4C

KDM5B Repression of stem cell genes to allow ESC differentiation into neurons.

KDM5C Repression of neuronal genes in non-neuronal cells. Neuronal survival and dendritic development.

KDM6A Induction of neural differentiation in hESC

Forebrain development antagonized by SMRT in isolated cortical progenitors. Neuronal differentiation in P19 cells. Neural commitment of ESC. BMP-induced dorsal interneurons generation in chick embryo neural tube. TGF $\beta$-induced neuronal differentiation in $\mathrm{mNSC}$.

KDM7A Neural differentiation in mESCs. Neural induction on early chick embryos.

Tectum development and neural survival in zebrafish embryos. Interaction with

PHF8 ZNF711 and regulation of JARID1C. Regulation of cytoskeleton-related genes neccesary for proper neurite formation.
Associated pathologies

Autism spectrum disorders.

\section{References}

Fukuda et al. 2011

Wang et al. 2014

Strobl-Mazzulla et al. 2010

Kantojarvi et al. 2010

Schmitz et al. 2011, Albert et al. 2013

X-linked mental retardation, autism Jensen et al. 2005, Tahiliani et al. 2007 spectrum disorders, epilepsy. Iwase et al. 2007, Adegbola et al. 2008

Kabuki syndrome.

Lederer et al. 2012, Shahhoseini et al. 2013

Jepsen et al. 2007, Burgold et al. 2008, Dai et al. 2010, Akizu et al. 2010, Estaras et al. 2012

Huang et al. 2010a, Huang et al. 2010b

$\mathrm{X}$ linked mental retardation, cleft Laumonnier et al. 2005, Qi et al. 2010, Tsukada et al. 2010, Kleine-Kohlbrecher et al. 2010, Asensio-Juan et al. 2012 